Res Publica. Revista de Historia de las Ideas Políticas ISSN-e: 1989-6115

https://dx.doi.org/10.5209/rpub.65064

\title{
Laclau: una política del antagonismo
}

\author{
Gustavo Patricio Guille*
}

Recibido: 31 de agosto de 2018 / Aceptado: 10 de junio de 2019

Resumen. El artículo presenta la noción de antagonismo como categoría central para comprender el pensamiento de Ernesto Laclau. Para ello recupera los distintos modos en que dicha noción es reformulada a lo largo de su recorrido teórico. De este modo, partiendo de la caracterización inicial de la noción de antagonismo desarrollada en Hegemonía y estrategia socialista, el artículo se centra en el análisis de las modificaciones posteriores de dicha categoría; las cuales son interpretadas respectivamente como una radicalización ontológica y una radicalización política del antagonismo. Finalmente, se destaca la importancia de esta noción para pensar una política radical que sostenga un proyecto emancipador frente a la hegemonía neoliberal.

Palabras clave: Antagonismo; Dislocación; Hegemonía; Política.

\section{[en] Laclau: a Politics of Atagonism}

Abstract. This paper focuses on the notion of "antagonism" as one of the main categories in Laclau's thought. It recovers the different ways in which this notion was recreated by Laclau throughout his work. Beginning with the first characterization of antagonism as it appears in Hegemony and socialist strategy, we aim to show the changes suffered by this notion, to understand them as an ontological and political radicalization of the antagonism. Finally, we underline the importance of this notion to think a radical politics together with and emancipation's project against the neoliberal hegemony.

Keywords: Antagonism; Dislocation; Hegemony; Politics.

Sumario: 1. Antagonismo como punto de ruptura con la tradición marxista. 2. Hacia una nueva conceptualización del antagonismo: el posmarxismo. 3. Radicalización ontológica del antagonismo: la dislocación. 4. Radicalización política del antagonismo: el populismo 5. Una política del antagonismo.

Cómo citar: Straehle, E. (2019). Laclau: una política del antagonismo, en Res Publica 22.2, 495-510.

El momento del antagonismo, en el que se hace plenamente visible el carácter indecidible de las alternativas y su resolución a través de relaciones de poder es lo que constituye el campo de "lo político".

E. Laclau, Nuevas reflexiones sobre la revolución de nuestro tiempo.

\footnotetext{
* Universidad de Buenos Aires, Argentina gustavopguille@gmail.com
} 
El presente artículo se propone abordar la noción de "antagonismo" en el pensamiento de Ernesto Laclau, en tanto resulta una categoría de análisis central para comprender tanto su concepción de lo político como la manera en que concibe la configuración de identidades políticas. Dado que la noción ha sufrido modificaciones a lo largo del desarrollo teórico de Laclau, organizaremos la exposición del modo siguiente: en primer lugar, realizaremos una aproximación general a la noción de antagonismo como alternativa a la idea marxista de "lucha de clases"; a continuación presentamos la noción tal como aparece desarrollada en Hegemonía y estrategia socialista (1985), analizando las críticas que el filósofo esloveno Slavoj Žižek realizara a la concepción del antagonismo elaborada por Laclau y Mouffe en Hegemonía..., lo que conduce a la reformulación del concepto por parte de Laclau en su trabajo Nuevas reflexiones sobre la revolución de nuestro tiempo (1990) y que interpretamos como una radicalización ontológica del antagonismo; por último, nos enfocamos en la formulación del antagonismo presentada en La razón populista (2005), destacando su importancia para pensar una política radical, encarnada en el populismo, que sostenga un proyecto emancipador frente a la hegemonía neoliberal.

\section{Antagonismo como punto de ruptura con la tradición marxista}

El interés de Laclau en la noción de "antagonismo" se remonta a los primeros años de su producción teórica. Como indica Mark Devenney ${ }^{1}$, Laclau analizó por primera vez la noción de antagonismo en un artículo aparecido en el año 1970 en la New Left Review ${ }^{2}$. El artículo abordaba la crisis argentina de mayo de 1969, que comenzó con una manifestación conjunta de estudiantes y sindicatos en Córdoba ${ }^{3}$. Allí Laclau se planteaba el siguiente interrogante: “¿por qué se unieron estudiantes de clase media con sindicalistas en oposición a la dictadura militar de Juan Carlos Onganía?"4. En el análisis de esta cuestión ya se encuentran presentes, afirma Devenney, "algunos elementos clave de la trayectoria teórica de Laclau"s: principalmente el hecho de que "el antagonismo no traza una línea divisoria clara entre clases" de manera que, como lo muestra el levantamiento en Córdoba, puede articularse "una alianza populista entre diferentes sectores de la sociedad [estudiantes de clase media y trabajadores

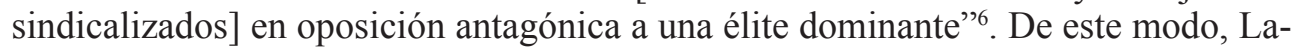
clau parece tener claro ya desde esa temprana época que "la ideología política no está determinada por la posición de clase"?.

La necesidad de re-pensar el concepto de antagonismo para romper con ciertos postulados del marxismo ortodoxo, a través de una crítica o debate interno en el seno de esta tradición, tiene una importancia decisiva durante todo el recorrido teórico de Laclau. Ese sigue siendo el problema medular en uno sus últimos textos publicados:

\footnotetext{
M. Devenney, "La política del antagonismo" en Debates y Combates. Edición homenaje a Ernesto Laclau, Buenos Aires, F.C.E., 2015, pp. 37-52.

E. Laclau, “Argentina: Imperialist Strategy in the May Crisis”, New Left Review, № 62, 1970, pp. 3-21.

El autor se refiere se refiere a los hechos ocurridos en Argentina el 29 y 30 de mayo de 1969 y conocidos popularmente como "el Cordobazo".

$4 \quad$ M. Devenney, op. cit., p. 38.

Ibidem. p. 39.

Ibidem.

Ibidem.
} 
"Antagonismo, subjetividad, política"8. En este ensayo, Laclau sostiene que a partir de la radicalización de la noción de antagonismo es posible escapar a tres premisas esencialistas presentes en el manifiesto inaugural del socialismo moderno -esto es, en El manifiesto comunista de Marx y Engels (1848)-, las cuales se encontrarían implícitas en las siguientes palabras: "La historia de toda sociedad hasta nuestros días no ha sido sino la historia de las luchas de clases". De aquí Laclau deduce tres premisas o postulados tradicionales del marxismo: primero, la historia de la humanidad sería un objeto unificado que poseería una estructura coherente y comprensible. Segundo, sería posible determinar los agentes de esta historia, es decir, las clases sociales. Tercero, que el tipo de relación que caracterizaría la interacción entre estos agentes sería la lucha .

Laclau se pregunta si estos tres postulados, estas tres dimensiones del discurso marxista pueden converger en un todo armónico. La respuesta es que ello sólo puede ser posible al precio de considerar la dimensión antagónica (la lucha) como ficticia y subordinada a la coherencia del todo estructural (la historia de la humanidad). En palabras del autor:

El antagonismo presupone la incompatibilidad entre elementos opuestos, mientras que la coherencia en el interior de la estructura implica la complementariedad entre sus momentos internos. Por lo tanto, si la estructura está constituida por momentos antagónicos, ella sólo puede conservar su coherencia al precio de que la dimensión antagónica se revele ficticia: es decir, un fenómeno de superficie detrás del cual -y a través del cual- opera una substancial unidad estructural. Esto significa que, siempre que prevalezca la dimensión totalizante, el momento antagónico está subordinado a una historia más profunda ${ }^{10}$.

Dicho en otros términos, el momento teóricamente objetivo del desarrollo histórico conformado por el nexo entre las fuerzas productivas y las relaciones de producción es, en la lógica marxista clásica, contradictorio y se resuelve en la conciliación dialéctica de los polos opuestos de acuerdo al esquema de la identificación entre racionalidad y realidad que Marx habría heredado de Hegel; mientras que el momento subjetivo de la lucha de clases es (o debería ser) propiamente antagónico y, por lo tanto, tendría que escapar a la conciliación dialéctica. De este modo, Laclau entiende que la lógica del discurso marxista no puede integrar de manera coherente el antagonismo sin contradicción propio de la conflictividad social y la contradicción sin antagonismo entre fuerzas y relaciones de producción ${ }^{11}$. Por otro lado, para nuestro autor, la relación capitalista/obrero no puede ser considerada como intrínsecamente antagónica; puesto que para que lo fuera habría que demostrar que "el antagonismo surge lógicamente de la relación entre el comprador y el vendedor de la fuerza de trabajo" " Pero eso es exactamente lo que no puede mostrarse. De la relación capitalista/obrero considerada como forma, es decir, como relación entre categorías

8 E. Laclau, "Antagonismo, subjetividad y política" en Los fundamentos retóricos de la sociedad, Buenos Aires: F.C.E., 2014, pp. 127-154.

$9 \quad$ Ibidem. p. 127.

$10 \quad$ Ibidem. p. 128.

11 E. Laclau, Nuevas reflexiones sobre la revolución de nuestro tiempo. Buenos Aires: Nueva Visión, 1993 [1990], pp. 22-23.

$12 \quad$ Ibidem. p. 25. 
económicas (y no entre personas reales), no surge ningún antagonismo. Es sólo si el obrero resiste a la extracción de plusvalía que el vínculo entre ambos pasa a ser antagónico $-\mathrm{y}$ ello es enteramente contingente, no puede deducirse de categorías lógicas-. En este sentido, ya desde sus trabajos de los años '70 para Laclau las clases no se constituyen al margen de las luchas, sino que es a partir de estas últimas que pueden surgir articulaciones antagónicas ${ }^{13}$.

Será partiendo de estos desacuerdos básicos que Laclau (junto con Chantal Mouffe) elaboraran en Hegemonía y estrategia socialista ${ }^{14}$ (1985) una noción de antagonismo alternativa -y que consideran más radical- a la presente en el esquema marxista de la lucha de clases.

\section{Hacia una nueva conceptualización del antagonismo: el posmarxismo}

En el marco de la reelaboración de la categoría gramsciana de hegemonía -a través de la articulación de elementos del postestructuralismo, el psicoanálisis freudiano y la deconstrucción derrideana, entre otros- que dará lugar a la emergencia del campo posmarxista inaugurado por Hegemonía y estrategia socialista ${ }^{15}$, Laclau y Mouffe otorgan un lugar central a la configuración de un nuevo concepto de antagonismo. Para ello pretenden deslindar su análisis no sólo respecto de la tradición marxista sino también de las corrientes históricas y sociológicas que han indagado frecuentemente acerca de cuáles son los antagonismos realmente existentes en la sociedad, preguntándose a la vez por qué y cómo surgen los mismos. Tomando distancia de estos abordajes, la pregunta laclausiana es más fundamental; en la medida en que trata de establecer qué es un antagonismo, qué es una relación antagónica, es decir, qué tipo de relación entre objetos supone. En este sentido, Laclau considera que la pregunta por el antagonismo debe ser ontológica, si es que se quiere avanzar más allá de las investigaciones sociológicas e históricas ${ }^{16}$.

Para dar respuesta a esta cuestión Laclau y Mouffe retoman los análisis realizados por la escuela de Galvano Della Volpe y, particularmente, de uno de sus discípulos: Lucio Colletti ${ }^{17}$. Colletti examina la distinción kantiana entre dos tipos posibles de oposición: la "contradicción lógica" y la "oposición real"; con el fin de establecer

13 Es necesario destacar que a pesar de su temprana inquietud por desmontar el esquema esencialista y teleológico de las categorías de la ortodoxia marxista, en sus primeros trabajos Laclau continua sosteniendo que todas las contradicciones sociales están sobredeterminadas por la lucha de clases, y que toda articulación antagónica se encuentra ligada a un elemento articulador privilegiado expresado a través de la noción "proyecto de clase". Cf. E. Laclau, Política e ideología en la teoría marxista. Capitalismo, fascismo, populismo. Madrid, Siglo XXI, 1977. Como desarrollaremos a continuación, la ruptura definitiva con lo que nuestro autor considera el marxismo esencialista se producirá en 1985 con la publicación de Hegemonía y estrategia socialista. Hacia una radicalización de la democracia escrito en colaboración con Chantal Mouffe.

14 E. Laclau, y C. Mouffe, Hegemonía y estrategia socialista. Hacia una radicalización de la democracia. Buenos Aires: F.C.E., 2010 [1985].

15 Como señalan los autores en el Prólogo a la Segunda Edición de Hegemonía y estrategia socialista, el término "posmarxismo" aparece sólo una vez, y de manera incidental, en la Introducción del libro (Laclau y Mouffe, 1985: 28); pero fue adoptado, en un comienzo sobre todo por sus detractores, como rótulo para referirse al trabajo de Laclau y Mouffe. Cf. E. Meiksins Wood, The Retreat from Class. A New “True” Socialism. London, Verso, 1986 y N. Geras, "Post-Marxism?” en New Left Review n 163 (may-jun), 1987, pp. 3-27.

16 E. Laclau y C. Mouffe, op. cit., p. 164 y E. Laclau, “Antagonismo, subjetividad y política”, op. cit., p. 128.

17 L. Colletti, "Marxism and the dialectic", New Left Review No 93, septiembre-octubre, 1975, pp. 3-29. 
cuál de estas categorías da cuenta de la especificidad de los antagonismos sociales. Lo primero que debemos esclarecer, entonces, es cómo se conciben estas dos categorías:

[La oposición real] coincide con el principio de contrariedad y obedece a la fórmula "A-B": cada uno de sus términos tiene una positividad propia, independiente de su relación con el otro. La segunda es la categoría de contradicción y obedece a la fórmula "A-no A": la relación de cada término con el otro agota la realidad de ambos. La contradicción tiene lugar en el campo de la proposición; sólo a un nivel lógico conceptual podemos incurrir en contradicciones. El primer tipo de oposición tiene lugar, en cambio, en el campo de los objetos reales ${ }^{18}$.

La conclusión que Colletti deriva de esta distinción es que los antagonismos no pueden ser comprendidos en términos de "contradicciones"; ya que éstas sólo tienen lugar en el plano conceptual, lo cual es incompatible con una filosofía materialista como el marxismo. Por lo tanto, los antagonismos deberían ser concebidos en términos de "oposiciones reales".

Laclau rechazará esta conclusión. El antagonismo no puede ser una oposición real. ¿Por qué? La respuesta es simple: una oposición real es un fenómeno que ocurre en el mundo natural; "un hecho material que obedece a leyes físicas positivas"19, tal como el choque entre dos rocas o entre dos vehículos. Pero en ello no hay nada antagónico. Comprender los antagonismos sociales en términos de una oposición real implicaría, por ejemplo, que lo antagónico en la lucha de clases pudiera manifestarse en el "acto físico por el que un policía golpea a un militante obrero"20. Ello no significa que Laclau y Mouffe acepten la otra opción analizada, es decir, caracterizar el antagonismo como contradicción. Por el contrario, también rechazan esa salida. Para los autores del hecho de aceptar proposiciones contradictorias tampoco se sigue, necesariamente, ninguna relación antagónica.

A pesar de la aparente oposición o dicotomía que se establece entre las posibles salidas $^{21}$, la imposibilidad de aceptar alguna de esas dos categorías para caracterizar el antagonismo se debe, fundamentalmente, a un rasgo que ambas comparten: el ser relaciones objetivas (entre objetos conceptuales en un caso y entre objetos físicos en otro). Es decir, es algo que los objetos ya son lo que hace inteligible la relación. Dicho de otro modo, son primero identidades plenamente constituidas que luego entran en relación entre sí: "es por el hecho de que A es plenamente A por lo que ser a la vez no-A es una contradicción"; de la misma manera "es porque A es también plenamente A por lo que su relación con B produce un efecto objetivamente determinable [una oposición real]"22.

En ambos casos nos encontramos frente a la ausencia de una negatividad constitutiva; mientras que para Laclau no puede haber antagonismo sin negatividad. Aquí

\footnotetext{
18 E. Laclau y C. Mouffe, op. cit., p. 165.

19 Ibidem, p. 166.

20 Ibidem.

21 De acuerdo con Laclau y Mouffe uno de los inconvenientes principales del análisis de Colletti es que "parte de una alternativa excluyente: o bien algo es oposición real, o bien es contradicción; esto procede de que en su universo hay lugar solamente para dos tipos de entidades: objetos reales y conceptos. Lo que equivale a decir que el punto de partida y supuesto de todo su análisis es la separación pensamiento/realidad”. E. Laclau y C. Mouffe, op. cit., p. 166.

$22 \quad$ Ibidem, p. 168.
} 
podría objetarse que la contradicción dialéctica (hegeliana y marxiana) está atravesada por la negatividad. Laclau reconoce esto destacando que algunos teóricos marxistas deseaban preservar la dimensión de negatividad inherente a una relación antagónica -claramente ausente en el caso de la oposición real teorizada por Colletti- pero dado que "la única negatividad a la que tenían acceso era la dialéctica, continuaron hablando de antagonismo en términos de contradicción" 23 . Sin embargo, como hemos adelantado, para Laclau en la contradicción dialéctica la negatividad nunca es constitutiva, sino tan sólo ficticia:

[La negatividad] está presente en el momento de la cadena dialéctica, pero ya tiene, en su interior, las simientes de su propia superación. En la unidad última del Espíritu Absoluto, todas las contradicciones encuentran el punto de su superación final. (...) Y, desde luego, una negatividad que es sólo el puente hacia una positividad más alta no puede ser radical y constitutiva ${ }^{24}$.

Por el contrario, Laclau afirma que el antagonismo debe entenderse como una relación entre fuerzas en la que la negatividad es un componente constitutivo inerradicable. Atribuir a la negatividad este papel constitutivo en la configuración de las relaciones antagónicas, implica aceptar que el orden social no puede estructurarse nunca como un todo objetivo, homogéneo y sin fisuras, es decir, como un todo completamente "reconciliado" consigo mismo. Lo que ocurre al nivel de la estructura social también se verifica al nivel de los "elementos" que forman parte de la misma. Por lo tanto, como afirma Laclau:

Para tener un antagonismo, la primera condición es que haya una interrupción (o un impedir la constitución) de una identidad plena. De modo que la construcción de un antagonismo es diferente, tanto de la oposición real como de la contradicción dialéctica, dado que estas dos últimas presuponen una identidad plena. Esto explica nuestra afirmación de que los antagonismos no son relaciones objetivas, sino relaciones en las que se muestran los límites en la constitución de la sociedad como orden objetivo ${ }^{25}$.

En la medida en que se encuentra habitado, asediado, desde su interior por relaciones antagónicas (por una negatividad) constitutivas que impiden su clausura definitiva, todo orden social se revela como una "objetividad fallida". Dicho con otras palabras, "el antagonismo constituye los límites de toda objetividad"26. En virtud de ello, toda objetividad debe ser considerada en términos de procesos de objetivación siempre parciales y precarios, esto es, fallidos. Esto vale tanto a nivel de la estructura social como de las identidades (subjetividades) que forman parte de ella. En conclusión: "Es porque lo social está penetrado por la negatividad -es decir, por el antagonismo- que no logra el estatus de la transparencia, de la presencia plena, y que la objetividad de sus identidades es plenamente subvertida" ${ }^{27}$.

\footnotetext{
E. Laclau, "Antagonismo, subjetividad y política", op. cit., p. 133.

Ibidem, p. 138.

Ibidem, p. 140.

E. Laclau y C. Mouffe, op. cit., p. 168.

Ibidem, p. 172.
} 
Ahora bien, esta definición de antagonismo como aquello que constituye los límites de toda objetividad convive en Hegemonía ... con una segunda definición; de acuerdo a la cual el antagonismo puede ser concebido como "la presencia del Otro que me impide ser totalmente yo mismo"28. Dado que las relaciones antagónicas no pueden darse a partir de identidades plenas, sino de la imposibilidad de constitución de las mismas, Laclau y Mouffe entienden que en la medida en que hay antagonismo ninguna de las identidades antagónicas puede constituirse como una presencia plena para sí. A diferencia de la oposición real y la contradicción que son concebidas como relaciones objetivas entre cosas y conceptos respectivamente, Laclau y Mouffe afirman que:

En la medida en que hay antagonismo yo no puedo ser una presencia plena para mí mismo. Pero tampoco lo es la fuerza que me antagoniza: su objetivo es ser un símbolo de mí no ser y, de este modo, es desbordado por una pluralidad de sentidos que me impide fijarlo como positividad plena ${ }^{29}$.

Como puede verse, el ser "objetivo" de la fuerza que me antagoniza es tan sólo un símbolo de mi no ser. Es porque un campesino no puede ser un campesino, indican los autores, por lo que existe un antagonismo con el propietario que lo expulsa de la tierra. Esta concepción del antagonismo permite sostener que en toda lucha política está en juego la constitución de la identidad; desmarcándose así de aquellos que sostienen que la lucha política es llevada adelante por sujetos pre-constituidos.

Slavoj Žižek (1993: 257) ha señalado que el gran logro de Hegemonía y estrategia socialista se hace patente en este novedoso concepto de antagonismo; ya que a través de él, "lejos de reducir toda la realidad a juegos de lenguaje, el campo socio-simbólico es concebido como estructurado en torno a una cierta traumática imposibilidad, en torno de una fisura que no puede ser simbolizada" ${ }^{30}$. Sin embargo, es también Žižek quien ha detectado cierto núcleo problemático en la noción de antagonismo en tanto éste es definido como "la presencia del Otro que me impide ser yo mismo"; es decir, en el lugar donde el antagonismo se encuentra vinculado con la noción estructuralista de posiciones de sujeto. El filósofo esloveno reconoce que a través de esa concepción del sujeto Laclau y Mouffe se proponen:

(...) Atacar a la clásica noción del sujeto como entidad sustancial y esencial, dada de antemano, que domina la totalidad del proceso social y que no es producida por la contingencia del propio proceso discursivo: contra esta noción ellos afirman que

\footnotetext{
Ibidem, p. 168.

Ibidem, p. 168.

30 S. Žižek, "Más allá del análisis del discurso" en E. Laclau, Nuevas reflexiones sobre la revolución de nuestro tiempo, op. cit., pp. 257-267. Para Laclau y Mouffe "si la lengua es un sistema de diferencias, el antagonismo es el fracaso de la diferencia y, en tal sentido, se ubica en los límites del lenguaje y sólo puede existir como disrupción del mismo - es decir, como metáfora- (...) El antagonismo escapa a la posibilidad de ser aprehendido por el lenguaje, en la medida en que el lenguaje sólo existe como intento de fijar aquello que el antagonismo subvierte". E. Laclau y C. Mouffe, op. cit., pp. 168-9. En consecuencia, los autores señalan que el antagonismo "muestra" -en el sentido en que para L. Wittgenstein lo que no se puede decir se puede mostrar-los límites de toda objetividad, es "testigo" de la imposibilidad de una sutura última del espacio social. Por otro lado, desde esta perspectiva, como afirma Devenney: "el antagonismo no se puede explicar en términos racionales ni empíricos" dado que "la experiencia del antagonismo es inherentemente política", es decir, se da a nivel ontológico. M. Devenney, op. cit., p. 42.
} 
lo que tenemos es una serie de posiciones particulares de sujeto (feminista, ecologista, democrática...) cuya significación no está fijada a priori: ellas cambian según el modo en que aquéllas son articuladas en una serie de equivalencias a través del excedente metafórico que define la identidad de cada una de esas posiciones ${ }^{31}$.

Pero, al mismo tiempo, considera que tan pronto como logramos identificarnos con un discurso determinado, es decir, tan pronto respondemos a la interpelación ${ }^{32}$ y asumimos cierta posición de sujeto, quedamos atrapados dentro de una ilusión ideológica. De manera que somos, por definición, engañados. ¿En qué consiste para Žižek la trampa ideológica intrínseca en la noción de posiciones de sujeto entrelazada por Laclau y Mouffe con la noción de antagonismo? Si se toma como ejemplo la lucha de clases como una relación antagónica, deberíamos aceptar que cada una de las fuerzas antagónicas impide a la otra lograr su plena identidad, es decir, llegar a ser lo que cada una realmente es. En la medida en que me reconozco a mí mismo en una interpelación ideológica - esto es, ocupando una posición de sujeto- como un «proletario», señala Žižek, estoy comprometido en la realidad social luchando contra el "capitalista", que bloquea mi pleno desarrollo, que me impide realizar mi pleno potencial. La ilusión ideológica reside en el hecho de que al comprender el antagonismo como "la presencia del otro que me impide ser yo mismo" (de acuerdo con una de las definiciones de Laclau y Mouffe), es el "capitalista", en tanto enemigo externo, el que le impide al "proletario" consumar su identidad, generando así la ilusión de que en caso de una "aniquilación final del enemigo antagónico", podría alcanzar la plena identidad consigo mismo; lo que conduciría nuevamente a la afirmación de un sujeto sustancial plenamente constituido y reconciliado ${ }^{33}$.

Por el contrario, si queremos escapar definitivamente a la idea de un sujeto sustancial (la cual es una de las apuestas principales del planteo de Laclau), es necesario pensar el antagonismo en su forma radical:

Para capturar la noción de antagonismo en su dimensión más radical debemos invertir la relación entre sus dos términos: no es el enemigo externo el que me impide alcanzar la identidad conmigo mismo, sino que cada identidad librada a sí misma, está ya bloqueada, marcada por una imposibilidad, y el enemigo externo es simplemente la pequeña pieza, el resto de realidad sobre el que "proyectamos" o "externalizamos" esta intrínseca, inmanente imposibilidad ${ }^{34}$.

Por lo tanto, para Žižek, es necesario distinguir entre el antagonismo en su forma radical, esto es, como límite de toda objetividad, como límite de lo social -“como la imposibilidad a partir de la cual se estructura el campo social" ${ }^{35}$-, al que denomina "antagonismo puro", del antagonismo entendido como relación entre posiciones de sujeto antagónicas.

31 S. Žižek, op. cit., p. 258.

32 Žižek considera que "la noción de posiciones de sujeto aún entra en el marco de la interpelación ideológica althusseriana como constitutiva del sujeto"; de ahí el uso de cierta terminología que remitiría al trabajo de L. Althusser. Ibidem, p. 259.

33 Ibidem, p. 259.

34 Ibidem, pp. 259-260.

35 Ibidem, p. 261. 


\section{Radicalización ontológica del antagonismo: la dislocación}

A partir de la publicación de Nuevas reflexiones sobre la revolución de nuestro tiempo, Ernesto Laclau realiza una serie de especificaciones y reelaboraciones en su teoría - en gran medida, debido a las observaciones de Slavoj Žižek que acabamos de comentar-, que afectan a su noción de antagonismo.

El punto de partida de las nuevas reflexiones efectuadas por Laclau es la fuerte vinculación que se establece entre el antagonismo y lo Real lacaniano. Como afirma nuestro autor: "si bien nuestro análisis del antagonismo no se deriva de la teoría lacaniana, puede superponerse en gran medida con la noción de Lacan de lo Real como un núcleo básico que resiste a la simbolización"36. Ahora bien, esto entraña una consecuencia importante para el presente estudio, puesto que dicha afirmación implica que toda estructura, toda objetividad, presenta una falta o falla estructural que impide su totalización definitiva, y que Laclau desarrollará en términos no ya de antagonismo sino de dislocación.

El antagonismo había sido caracterizado por Laclau como un "exterior constitutivo". Esto es, un "exterior" que bloquea la identidad del "interior" pero que a la vez, sin embargo, la hace posible; es decir, es tanto condición de posibilidad como de imposibilidad de su constitución. Ahora bien, en esta nueva etapa Laclau entiende que al hablar de antagonismo ya estamos en presencia de un principio de estructuración discursiva o simbólica de algo ontológicamente más profundo: la dislocación. Como el autor observa retrospectivamente:

El antagonismo ya es una forma de inscripción discursiva -es decir, de dominiode algo más primario que, desde Nuevas reflexiones sobre la revolución de nuestro tiempo, comencé a llamar "dislocación". [Más aún] No todas las dislocaciones necesitan ser construidas de manera antagónica ${ }^{37}$.

Como indica Yannis Stavrakakis ${ }^{38}$, el antagonismo se sitúa en el orden simbólico de la realidad, "denotando la relación entre proyectos discursivos diferentes, pero ya articulados, que compiten por la hegemonía”, mientras que la dislocación pertenece al orden de lo real (en sentido lacaniano). Puede decirse, entonces, que la dislocación es, tanto analítica como ontológicamente, anterior al antagonismo; de ahí que pueda afirmarse que aquella es la condición de posibilidad no sólo del antagonismo sino de la política en general, entendida ésta como práctica hegemónica. En palabras del intelectual argentino: "hay política porque hay subversión y dislocación de lo social" 39 .

Por otro lado, Laclau no sólo reconoce que el antagonismo es una respuesta (o un intento de respuesta) en el orden simbólico ante la falta (lack) original de la estructura social -es decir, frente a la dislocación-, sino que además entiende que la relación antagónica no es una respuesta necesaria a esa dislocación constitutiva:

\footnotetext{
36 E. Laclau, Nuevas reflexiones sobre la revolución de nuestro tiempo, op. cit., 83.

37 E. Laclau, “Atisbando el futuro" en Critchley, S. y Marchart, O. (comps.), Laclau. Aproximaciones críticas a su obra, Buenos Aires, F.C.E., 2008, pp. 347-404, p. 394.

38 Y. Stavrakakis, La izquierda lacaniana. Psicoanálisis, teoría, política. Buenos Aires, F.C.E., 2010, p. 93.

39 E. Laclau, Nuevas reflexiones sobre la revolución de nuestro tiempo, op. cit., p. 77.
} 
(...) Se puede experimentar una dislocación en la experiencia y atribuirla a la ira de Dios, atribuirla al castigo de los pecados, atribuirla a la intervención de algunos agentes misteriosos que están operando en esa sociedad, atribuirla a los judíos o a cualquier otro grupo victimizado. La idea de construir, de vivir esa experiencia de la dislocación como antagónica, sobre la base de la construcción de un enemigo, ya presupone un momento de construcción discursiva de la dislocación, que permite dominarla, de alguna manera, en un sistema conceptual que está a la base de cierta experiencia ${ }^{40}$.

De este modo, el antagonismo presenta un carácter enteramente contingente dado que es posible "expresar" la dislocación a través de inscripciones discursivas que no impliquen una relación antagónica ${ }^{41}$. La dislocación, por tanto, es el momento de lo Real que no puede ser subsumido dentro del orden simbólico. Dicho en otros términos, "dislocación" será entonces el concepto utilizado para pensar que la estructura tiene una falla constitutiva y que, por lo tanto, fracasa al constituirse como una objetividad plena. Este carácter de incompletitud de la estructura, el cual conlleva la inestabilidad y la radical contingencia de todo orden, es también concebido por Laclau en los términos derrideanos de la indecidibilidad estructural.

Ahora bien, ¿por qué afirmar que estas modificaciones implican una radicalización del antagonismo? Y más aún, ¿por qué esa radicalización tendría un carácter ontológico?

La respuesta a la primera de estas cuestiones se ha anticipado, en buena medida, en los párrafos anteriores de este apartado. Consideremos nuevamente los puntos centrales del movimiento realizado por Laclau para no dejar lugar a dudas. Partimos de una de las definiciones del antagonismo brindadas en Hegemonía y estrategia socialista según la cual el antagonismo es caracterizado como "la presencia del otro que me impide ser yo mismo". Los señalamientos críticos realizados por Slavoj Žižek ponen de manifiesto que detrás de esta definición puede esconderse una ilusión ideológica, la cual consistiría en la creencia que ante una posible eliminación o desaparición de la alteridad antagónica pudiera por fin conquistarse un ser (yo)

40 E. Laclau, Hegemonía y antagonismo. Conferencias de Laclau en Chile, 1997. Villalovos-Ruminott (ed.), Buenos Aires, Editorial Cuarto Propio, 2002, p. 81.

41 La contingencia no implica que estemos frente a un conjunto de relaciones puramente externas y aleatorias entre las identidades, sino sólo "la imposibilidad de fijar con precisión -es decir, en relación con una totalidad necesaria- tanto las relaciones como las identidades". E. Laclau, Nuevas reflexiones sobre la revolución de nuestro tiempo, op. cit., p. 37. Por lo tanto, lo que tenemos es un campo de identidades puramente relacionales que no logran nunca constituirse plenamente. De ello se sigue, como reconoce acertadamente Ricardo Camargo Brito, que la teorización de Laclau sobre la noción de antagonismo no sólo rompería con la noción marxiana clásica de "lucha de clases", sino que además evitaría el carácter totalizante y esencialista atribuido al criterio de distinción schmittiano amigo-enemigo. Cf. R. Camargo Brito, "Rethinking the Political. A Genealogy of the "Antagonism" in Carl Schmitt through the Lens of Laclau-Mouffe-Žižek" en The New Centennial Review, vol 13, $n^{\circ} 1,2013$, pp. 161-188. Por otro lado, como afirma Oliver Marchart, resulta más o menos evidente que todos los ejemplos de Laclau respecto de una forma no antagónica de significar la dislocación "están lejos de ser no políticos". En una situación dada puede experimentarse la dislocación de las sedimentaciones sociales a través del acaecimiento de un terremoto - es decir, de manera no antagónica-; sin embargo, es posible interpretar el terremoto como un fenómeno natural o como expresión de la "ira de Dios": "en ambos casos la red global de relaciones de poder (del discurso de la ciencia moderna o del sistema de creencias de la Iglesia Católica) tendrá que estar ya en funcionamiento, instituida políticamente, para que esa interpretación tenga éxito”. O. Marchart, El pensamiento político posfundacional. La diferencia política en Nancy, Lefort, Badiou y Laclau. Buenos Aires, F.C.E., 2009, pp. 198-199. 
plenamente constituido, un sí mismo sin fisuras. La salida a esta "trampa ideológica" se encuentra en la radicalización de la noción de antagonismo entendida ya no como "la presencia del otro que me impide ser yo mismo", sino como aquello que señala "los límites de toda objetividad".

Esa radicalización toma en Laclau el nombre de "dislocación" y denota el hecho de que toda objetividad, toda identidad, todo orden social se encuentra constitutivamente dislocado, subvertido, al estar atravesado por una alteridad que a la vez que lo niega y limita, le permite ser. Nuestro autor se ha referido a ello en términos de "la imposibilidad de la sociedad".

Para clarificar esta última expresión, en relación al tema que nos ocupa en este apartado, es necesario entrelazar el concepto de dislocación (como radicalización del antagonismo) con la teoría laclausiana del discurso; pues ello permitirá dar cuenta, en toda su complejidad, de la ontología (política) post-fundacional elaborada por Ernesto Laclau.

Como puede verse en Hegemonía y estrategia socialista y, aún con mayor claridad en el texto escrito (también en colaboración con Mouffe) en respuesta a Norman Geras $^{42}$, Laclau entiende que todo ser se constituye discursivamente y que "toda configuración social es una configuración significativa" ${ }^{\text {"43 }}$. Ahora bien, no hay estructura discursiva, significativa, que se realice sin pérdida, sin resto; pues no hay posibilidad de que el discurso logre alcanzar una representación plena de la realidad. En el seno de toda estructura simbólica/discursiva, como indica Lacan -a quien Laclau sigue en este punto-, hay una falta constitutiva, una brecha ontológica, un resto o fisura, que implica la imposibilidad radical de un cierre o clausura definitiva; se trata de una falla (dislocación) constitutiva que cuestiona la plenitud y consistencia del ser y "pone de manifiesto la falta-en-ser" ${ }^{4}$. De este modo, la introducción de la noción de falta -en paralelo a la de dislocación- en esta etapa del pensamiento de Laclau lo ha llevado a resaltar los límites de la significación; otorgando a dichas categorías una función ontológica. En este sentido, la falta adquiere el estatuto de un fundamento ausente que revela el ser siempre ya dislocado de toda estructura.

Como hemos visto, la falta, en tanto fundamento ausente, juega un papel estructural cumpliendo una función ontológica: implica la posibilidad-imposibilidad de constitución de toda estructura social significativa; de manera tal que al mismo tiempo que imposibilita su clausura definitiva, permite la fijación parcial y precaria del orden social. De acuerdo con Laclau, la dislocación muestra que lo social es irreductible, en última instancia, a una presencia plena; pero precisamente por eso son necesarios los intentos por suturar de manera precaria esa apertura constitutiva. Esos intentos son los que se llevan adelante a través de la política hegemónica, o de la política entendida como hegemonía.

En consecuencia, el discurso (proyecto) hegemónico, en tanto discurso (proyecto) político, consistirá en un intento por articular diferentes elementos discursivos -frente a, o en contraposición con, otros discursos o proyectos hegemónicos antagónicos- en un esfuerzo por estructurar un campo de significado que fije, siempre

42 E. Laclau y C. Mouffe, "Posmarxismo sin pedido de disculpas" en E. Laclau, Nuevas reflexiones sobre la revolución de nuestro tiempo, op. cit., pp. 111-145.

$43 \quad$ Ibidem, p. 114.

44 G. Aznárez y M. Vargas, “Ontología de la falta” en Biset, E. y Farrán, R. (ed.), Ontologías políticas. Buenos Aires, Imago Mundi, 2011, p. 155. 
parcialmente, las identidades de los objetos, los sujetos y las prácticas, en un sentido particular $^{45}$. De aquí se desprende que el análisis de la especificidad de los antagonismos, es decir, del esclarecimiento de las condiciones históricas que posibilitan cada articulación antagónica, se convierte en un punto crucial de la teoría de Laclau; pues como afirma Urs Stäheli:

Dado que los antagonismos naturales no existen, la construcción del antagonismo se convierte en una sede potencial de lo político. En vez de presuponer que hay un antagonismo pre "existente" que es preciso analizar, es necesario mostrar las estrategias particulares que construyen el antagonismo específico ${ }^{46}$.

Como hemos mostrado a lo largo de este apartado, la importancia del concepto de "dislocación" - en tanto radicalización ontológica del antagonismo-radica en que no sólo es condición de posibilidad de éste último, sino de la política en general.

\section{Radicalización política del antagonismo: el populismo}

En el apartado anterior se introdujo la distinción conceptual que Laclau establece, a partir de Nuevas reflexiones sobre la revolución de nuestro tiempo, entre dislocación $\mathrm{y}$ antagonismo. La distinción se sostiene fundamentalmente en que el antagonismo pasa a ser concebido como una inscripción discursiva -entre otras posibles- de algo más "profundo" y "primario": la dislocación. Ahora bien, para Laclau el antagonismo conserva una particularidad que tendrá una importancia capital en la conceptualización laclausiana del populismo desarrollada en La razón populista (2005), y que de acuerdo a nuestra lectura puede ser interpretada como una radicalización política del antagonismo respecto de la caracterización de dicho concepto realizada en Hegemonía ...: esa particularidad del antagonismo consiste en que éste produce una fractura dicotómica del espacio social.

Para comprender de manera adecuada este nuevo desplazamiento en el concepto de antagonismo es necesario dar cuenta del lugar que ocupa en el armazón conceptual de La razón populista. Alejado ya del lenguaje teórico y la racionalidad del marxismo clásico e introduciendo en su concepción del populismo numerosos aspectos pertenecientes al psicoanálisis freudiano y lacaniano, la finalidad del nuevo planteo de Laclau es presentar un enfoque alternativo que rescate al populismo de la posición marginal a la que había sido confinado en el discurso de las ciencias sociales. En tal sentido, el objetivo de Laclau consiste en invertir esa perspectiva de análisis: en lugar de abordar el populismo a partir de un modelo de racionalidad preconcebido

$45 \quad$ Esa fijación parcial de sentido es posible gracias a la construcción de puntos nodales producto de las prácticas articulatorias. Ello le permite a Laclau sostener que en la medida que lo social no tiene esencia, no es más que producto de articulaciones discursivas. Dicho de otro modo, en la medida en que la sociedad no puede constituirse de manera plena como el despliegue de una esencia, es que puede afirmarse que la "sociedad es imposible". Es decir, no existe la posibilidad de fundar un orden social completamente cerrado sino sólo de establecer un orden hegemónicamente instituido. Esto implica que el "cierre" hegemónico, resultado de la fijación parcial de sentido instaurada por los puntos nodales o significantes vacíos, nunca es un cierre absoluto sino que más bien supone "efectos suturantes".

46 U. Stäheli, "Figuras rivales del límite. Dispersión, transgresión, antagonismo e indiferencia" en Critchley, S. y Marchart, O. (comps.), op. cit., pp. 296-297. 
-dentro del cual no resulta posible hacerlo encajar, lo que deriva en su marginalización-, el autor intenta ampliar el modelo de racionalidad encontrando las lógicas que subyacen a la configuración populista. De este modo:

(...) en lugar de comenzar con un modelo de racionalidad política que entiende al populismo en términos de lo que le falta -su vaguedad, su vacío ideológico, su anti-intelectualidad, su carácter transitorio-, hemos ampliado el modelo o la racionalidad en términos de una retórica generalizada (la cual, como veremos, puede ser denominada "hegemonía"), de manera que el populismo aparezca como una posibilidad distintiva y siempre presente de estructuración de la vida política ${ }^{47}$.

Al mismo tiempo, Laclau opera otro desplazamiento clave para la formulación de su nuevo enfoque del populismo: sugiere pensar el concepto de populismo en términos de lógica política y no en virtud de la asignación de contenidos sociales o ideológicos. Si este nuevo enfoque es correcto, afirma Laclau, "podríamos decir que un movimiento no es populista porque en su política o ideología presenta contenidos reales identificables como populistas, sino porque muestra una determinada lógica de articulación de esos contenidos -cualesquiera sean estos últimos-"'48.

Ahora bien, para determinar la especificidad del populismo como lógica articulatoria, nuestro autor parte de la categoría de "demanda" como unidad mínima de análisis, dado que partir del grupo como elemento ya constituido implicaría comprenderlo como una "realidad" o "entidad" social previamente existente (con el consecuente riesgo de recaer en una posición esencialista), respecto de la cual el populismo sólo podría ser considerado como un epifenómeno que vendría a expresar la ideología o los contenidos presentes en dicho grupo.

De acuerdo con Laclau, el término demand (demanda) tiene en inglés dos sentidos que le permitirán realizar una distinción central en la economía de su esquema teórico. Por un lado, demand tiene el significado de "petición"; mientras que por otro adopta el sentido más activo de "demandar" o "reclamar" algo a alguien. Será en el pasaje del primer significado al segundo, en la transición desde la petición al reclamo o exigencia donde para Laclau podrá encontrarse uno de los primeros rasgos definitorios del populismo. Esa distinción y la consecuente transición de un sentido a otro resultan de suma importancia para nuestro autor, en la medida en que permiten establecer la diferenciación entre demandas democráticas y demandas populares. Para sostener esta distinción es necesario apelar, a su vez, a dos lógicas divergentes de constitución de lo social: la lógica de la diferencia y la lógica de la equivalencia.

La distinción entre demandas democráticas y demandas populares se sostiene entonces en función del tipo de lógica de constitución social al que respondan. En este sentido una demanda será democrática si, satisfecha o no, permanece aislada; es decir, si no ha entrado por el momento (a pesar de permanecer insatisfecha) en una cadena de articulación equivalencial con otras, o si (segunda posibilidad) ha sido absorbida -esto es, si ha sido satisfecha- diferencialmente por el sistema institucional vigente. En este caso estaremos en presencia de la lógica de la diferencia como instancia privilegiada de constitución de lo social. Por el contrario, las demandas po-

E. Laclau, La razón populista, Buenos Aires, F.C.E., 2005, pp. 27-28.

48 E. Laclau, "Populismo, ¿qué nos dice el nombre?" en Panizza, F. (comp.), El populismo como espejo de la democracia, Buenos Aires, F.C.E., 2009, pp. 51-70, p. 52. 
pulares son aquellas que logran articularse equivalencialmente con otras demandas, a través de lo cual comienzan a prefigurar, de manera incipiente, al "pueblo" como sujeto político. Aquí es la lógica de la equivalencia la que predomina como lógica de constitución político-social. Cabe destacar, sin embargo, que si bien estas dos lógicas son finalmente incompatibles entre sí, se necesitan, no obstante, la una a la otra como condiciones necesarias para la construcción de lo social; de modo que esto último no es otra cosa que el locus de una tensión irresoluble entre ambas ${ }^{49}$.

Ahora bien, si la articulación equivalencial de demandas es condición necesaria para el surgimiento del pueblo, ello no es suficiente por sí mismo. Se requiere además del establecimiento de una frontera antagónica que separe al "pueblo" de los poderosos, de los opresores. Así, la creación de esa frontera interna es para Laclau un rasgo indispensable de la configuración populista. De esta manera, los discursos populares equivalenciales se caracterizan por dividir lo social en dos campos antagónicos: el poder o "los de arriba" y "los de abajo". Dicho en otros términos, "nosotros" (el pueblo) y "ellos" (los enemigos del pueblo). Vemos que aquí está operando de manera clara una intensificación política del antagonismo, pues a partir de la noción de frontera antagónica se concibe a la sociedad como dividida en "dos campos irreductibles estructurados alrededor de dos cadenas equivalenciales incompatibles" 50 . La radicalidad del corte se manifiesta en la imposibilidad de su representación conceptual: el mismo no puede ser deducido a partir de una secuencia o derivación lógica (objetiva). Por el contrario, el momento del corte, es decir, el momento antagónico en cuanto tal, dependerá de un proceso de construcción política (hegemónica) contingente.

Por este motivo, la "contradicción" en su sentido dialéctico es totalmente incapaz de capturar lo que está en juego en un antagonismo social. (...) Si el antagonismo es, por el contrario, estrictamente constitutivo, la fuerza antagónica muestra una exterioridad que puede ser, ciertamente, vencida, pero que no puede ser dialécticamente recuperada ${ }^{51}$.

Esta "exterioridad" de la fuerza antagónica que opera en el marco de la división dicotómica generada por la articulación equivalencial populista, no significa que ésta enfrente dos términos positivos plenamente constituidos a partir de sí mismos; lo que proporciona cierta unidad al pueblo (a ese "nosotros") es un "afuera constitutivo" - una exterioridad interior-, el cual al tiempo que contribuye a configurar esa identidad imponiéndole un límite, la amenaza. "Este estatuto paradojal del «afuera

49 E. Laclau, La razón populista, op. cit., p. 106-107. Algo similar podría afirmarse respecto de las demandas. Como señala Paula Biglieri la distinción entre demandas democráticas y populares no debe ser concebida en términos de una oposición binaria en la cual sería posible establecer "de manera completamente clara y distinta la separación" entre unas y otras; puesto que no se trata de "átomos de sentido" que se "excluyan mutuamente". Más bien, habría que considerar que siempre hay una huella de lo otro de sí que las contamina. En este sentido, en las demandas democráticas podemos encontrar la huella de la equivalencia, y en las demandas populares la huella de la diferencia. Por lo tanto, "no sólo siempre está abierta la posibilidad de que, por ejemplo, una demanda democrática que ha sido absorbida e inscripta en la institucionalidad pueda volver a reactivarse como tal, sino que pueda devenir en popular en la medida en que entre en equivalencia con otras". P. Biglieri, "El concepto de populismo. Un marco teórico” en P. Biglieri \& G. Perelló (comps.), En el nombre del pueblo. La emergencia del populismo kirchnerista, San Martín, UNSAM. 2007, pp. 15-53, p. 40.

50 Ibidem, p. 110.

51 Ibidem., p. 112. 
constitutivo» es lo que le confiere el carácter de dislocada a toda identidad" 52 . Por otro lado, vemos aquí como una fuerza antagónica derrotada no puede ser completamente absorbida, recuperada, por el bando vencedor; la radicalidad política del antagonismo queda así expresada por esa exterioridad que no puede ser reapropiada.

La posición de Laclau da aquí un giro de $180^{\circ}$ grados respecto de lo sostenido en Hegemonía y estrategia socialista. En este último, si bien Laclau y Mouffe ya sostenían que la posición popular de sujeto es aquella que "se constituye sobre la base de dividir al espacio político en dos campos antagónicos" ${ }^{53}$, la misma era considerada por los autores como un fenómeno político residual o periférico; debido a que "las condiciones de la lucha política en el capitalismo maduro se alejan cada vez más del modelo del siglo XIX de una tajante «política de fronteras»" ${ }^{54}$. De este modo, los autores concluían:

Hablaremos pues de luchas democráticas en los casos en que éstas supongan una pluralidad de espacios políticos, y de luchas populares, en aquellos otros casos en que ciertos discursos construyen tendencialmente la división de un único espacio político en dos campos opuestos. Pero está claro que el concepto fundamental [el subrayado es nuestro] es el de "lucha democrática", y que las luchas populares sólo constituyen coyunturas específicas, resultantes de una multiplicación de efectos de equivalencia entre las luchas democráticas ${ }^{55}$.

Como queda claro por lo expuesto en este apartado, el cambio de posición es notable respecto a la elaboración laclausiana desarrollada en La razón populista, en la medida en que la construcción de una frontera antagónica es considerada como esencial en la conformación del pueblo como sujeto político y, por lo tanto, pasa a ser el eje central de una política emancipatoria que tenga por objetivo subvertir el orden institucional vigente. De este modo, como hemos querido mostrar, estamos en presencia de una radicalización política del antagonismo que en el envite por la fractura dicotómica del espacio social -en el marco del cual hay que una plebs, una parte de la comunidad, los desposeídos, que reclama ser el único populus legítimo- ya no apuesta por la democracia radical sino por el populismo como motor de cambio político y social.

\section{Una política del antagonismo}

El recorrido que hemos puntuado a lo largo de estas páginas ha tenido por objetivo poner de manifiesto la centralidad que el concepto de antagonismo tiene a lo largo de toda la trayectoria teórica de Ernesto Laclau. Así, en un primer momento hemos indicado de qué manera el concepto de antagonismo fue concebido por Laclau como una herramienta indispensable para romper con el paradigma marxista de la "lucha de clases", que ya en sus trabajos de la década del '70 consideraba como insuficien-

\footnotetext{
52 P. Biglieri, "El concepto de populismo. Un marco teórico", op. cit., p. 41.

53 E. Laclau y C. Mouffe, Hegemonía y estrategia socialista. Hacia una radicalización de la democracia, op. cit., p. 175.

$54 \quad$ Ibidem, p. 177.

55 Ibidem, p.181.
} 
te para dar cuenta de la complejidad de los fenómenos políticos. Posteriormente, analizamos lo que fuera la primera definición propiamente "posmarxista" de antagonismo -aquella que distingue el antagonismo de la oposición real y la contradicción lógica-, mostrando cierta ambivalencia presente en la misma, así como algunas críticas posibles que se desprendían de una de las caracterizaciones. A partir de allí, afrontamos el eje central del presente ensayo: pensar los posteriores desarrollos de la noción de antagonismo en los trabajos de Laclau en términos de una radicalización ontológica y una radicalización política del antagonismo, respecto de su primera definición esbozada en Hegemonía y estrategia socialista.

En este sentido, las distintas formulaciones, alteraciones y rectificaciones dan cuenta de la importancia capital que para el autor y su teoría reviste este concepto. Al mismo tiempo que son índice de la necesidad de re-adaptar dicha categoría a las nuevas modulaciones que se van operando en la teoría laclausiana de la hegemonía sin perder nunca su papel medular. Por lo tanto, siguiendo la hipótesis de la radicalización, entendemos que el antagonismo no deja de ganar protagonismo ontológico-político en el pensamiento de Laclau, tanto en el marco de su teoría de la hegemonía y en su formulación de la lógica populista, como en su concepción de lo político.

En este sentido, para Laclau la lógica del antagonismo es la que preside la escena política. Pues da cuenta de una hendidura original, de un conflicto irreductible, cuyo corolario implícito es el reconocimiento de la imposibilidad constitutiva de la clausura total de la estructura social y, por ende, denota la necesidad de la política (hegemónica) para realizar el cierre parcial del espacio social. De este modo, frente a una racionalidad neoliberal que pretende instaurar un ordenamiento social sin brecha, sin resto (a lo sumo con residuos humanos o no, que siempre pueden ser reutilizables o re-inscribibles en su lógica) y que licúa el antagonismo en términos la libre competencia en el mercado, para Laclau resulta indispensable la afirmación tanto una dislocación constitutiva (a nivel ontológico) como una radicalización política del antagonismo que realice una fractura dicotómica del espacio social, para sostener un proyecto emancipador y una política radical que se presente como alternativa al orden vigente. 